\title{
Effect of concomitant anti-solvent engineering on perovskite grain growth and its high efficiency solar cells
}

\author{
Tong Liu ${ }^{1,2}$, Xiaofei Dong ${ }^{1,2^{*}}$, Juncong $\mathrm{Li}^{1,2}$, Hongli Liu ${ }^{1,2}$, Shirong Wang ${ }^{1,2}$ and Xianggao $\mathrm{Li}^{1,2^{*}}$
}

ABSTRACT The grain boundaries and interface properties in the active layers of perovskite solar cells (PSCs) are important factors affecting the performances of the devices. In this work, a simple and fast concomitant annealing process is established by inducing the secondary growth of the grains using the antisolvent $o$-dichlorobenzene $\left(\mathrm{o}-\mathrm{PhCl}_{2}\right)$ or chlorobenzene $(\mathrm{PhCl})$ to suppress the volatilization of solvent molecules during the $\mathrm{FA}_{0.80} \mathrm{MA}_{0.15} \mathrm{Cs}_{0.05} \mathrm{~Pb}\left(\mathrm{I}_{0.85} \mathrm{Br}_{0.15}\right)_{3} \quad\left(\mathrm{FA}, \mathrm{CH}_{5} \mathrm{~N}_{2}^{+}\right.$, formamidine; MA, $\mathrm{CH}_{3} \mathrm{NH}_{3}{ }^{+}$, methylamine) film annealing procedure. The effects of anti-solvent molecules on the phase transformation, grain boundary fusion and morphology evolution of perovskite films are systematically investigated by $\mathrm{X}$-ray diffraction (XRD) and scanning electron microscopy (SEM). The results indicate that anti-solvent molecules can inhibit solvent evaporation in the active layers and promote crystallite dissolution and ordered secondary growth along the surfaces of large grains. That can promote the formation of large grains and the passivation of surface defects, and can be favorable for the separation and transportation of photocarriers in the active layer. Consequently, the power conversion efficiency (PCE) of PSCs can be effectively improved, with a PCE of $\mathbf{2 0 . 7 2 \%}$ being achieved by a secondary growth perovskite film optimized with $\mathrm{o}-\mathrm{PhCl}_{2}$. Moreover, the efficiency remains at $85 \%$ of its initial value after $2400 \mathrm{~h}$ of treatment in a natural indoor environment with a relative humidity of $45 \pm 5 \%$.

Keywords: anti-solvent vapor annealing, perovskite grains, secondary growth, defect passivation, solar cells

\section{INTRODUCTION}

Solar cells with $\mathrm{CH}_{3} \mathrm{NH}_{3} \mathrm{PbI}_{3}$-type active layers have been increasingly considered as a crucial research direction in the renewable energy field over the past decade [1,2], and the highest certified power conversion efficiency (PCE) of perovskite solar cell (PSC) is $25.2 \%[3,4]$. The quality of perovskite active layer is the key factor affecting the performance of the PSCs. Controlling the grain growth process has been proven to be feasible to obtain perovskite films with high crystallinity, large grains [5], few grain boundaries, low trap densities and carrier recombination rate [6,7].

Advanced engineering approaches for improving the film quality can be classified into two categories: (a) controlling the growth rate by changing the synthesis, such as additive engineering [8] and solvent engineering $[9,10]$; (b) regulating the film morphology by post-treatment, including interface modification [11,12] and solvent vapor-assisted (SVA) methods [13,14]. The latter focuses on the induction of the secondary grain growth to improve the film quality and device performance. Unlike interface modification, the SVA method avoids introducing impurities and effectively reduces the interface barrier, which facilitates the transportation of photogenerated carriers and enhances the photocurrent of the device [15]. Xiao et al. [16] reported that annealing a perovskite film in polar solvent $\mathrm{N}, \mathrm{N}$-dimethylformamide (DMF) vapor yielded large-size grains exceeding $1 \mu \mathrm{m}$, and the best device PCE reached 15.6\%. Liu et al. [17] demonstrated that constructing a mixed solvent vapor atmosphere of dimethyl sulfoxide (DMSO), DMF, and $\gamma$-butyrolactone for a heated perovskite film resulted in the dissolution and regrowth of crystallites. The optimized perovskite/phenyl- $\mathrm{C}_{61}$-butyric acid methyl ester (PCBM) planar solar cell exhibited a PCE of $13 \%$. Xiao et al. [18] reannealed a $\mathrm{CH}_{3} \mathrm{NH}_{3} \mathrm{PbI}_{3}$ film in DMSO vapor for $28 \mathrm{~min}$ after the film was annealed at $95^{\circ} \mathrm{C}$ for $2 \mathrm{~min}$ to reduce the carrier activation energy at the grain boundaries and proposed a grain coarsening model. After

${ }^{1}$ School of Chemical Engineering and Technology, Tianjin University, Tianjin 300350, China

${ }^{2}$ Collaborative Innovation Center of Chemical Science and Engineering (Tianjin), Tianjin 300072, China

* Corresponding authors (emails: dongxiaofei@tju.edu.cn (Dong X); lixianggao@tju.edu.cn (Li X)) 
the DMSO vapor process, the perovskite film exhibited a more uniform morphology and a significantly enhanced light absorption intensity, which resulted in the enhancement of the short-circuit current density $\left(J_{\mathrm{sc}}\right)$ from 19.46 to $21.67 \mathrm{~mA} \mathrm{~cm}^{-2}$ and the improvement of PCE from $15.13 \%$ to $17.64 \%$. Li et al. [19] proposed that $\mathrm{PhCl}$ assisted annealing improved the film quality and obtained a PCE of $14.79 \%$, but the annealing mechanism was not illustrated. Moreover, Yu et al. [20] declared that an ultrasmooth $\mathrm{MAPbI}_{3-x} \mathrm{Cl}_{x}$ (MA, $\mathrm{CH}_{3} \mathrm{NH}_{3}{ }^{+}$, methylamine) perovskite film was obtained by treating with DMF and $\mathrm{PhCl}$ mixed solvent (with volume ratio of 1:20) vapor without thermal annealing. As a result, the PCE of the inverted device reached $16.4 \%$. The abovementioned studies indicate that the use of polar solvent, anti-solvent or mixed solvent during different annealing stages of the perovskite active layer could further promote grain growth and improve the device efficiency [21]. However, there are problems with solvent annealing, such as excessive solvent causing over-dissolution, difficulty in accurately controlling the solvent ratio, and sensitive processing time, which lead to low device efficiencies [17,22]. Additionally, the regulatory mechanism of grain growth during antisolvent annealing needs to be further studied to effectively improve the PCE and stability of PSCs.

Unlike previous work, this study constructs a simple and fast concomitant annealing approach in a closed space to replace the stepwise solvent annealing method performed in glass Petri dish $[19,20]$ and investigates the effect of anti-solvent vapor on the growth mechanism of perovskite films. The volumes of $o$-dichlorobenzene ( $o$ $\mathrm{PhCl}_{2}$ ) and chlorobenzene $(\mathrm{PhCl})$ were adjusted to control the vapor pressure for high-quality films. The effect of anti-solvent vapor treatment on the phase transformation of perovskite film was characterized by X-ray diffraction (XRD), and the mechanism of anti-solvent molecules on the morphology evolution of perovskite film was further revealed by scanning electron microscopy (SEM). The influence of anti-solvent vapor process on the defect density in perovskite film was systematically investigated by steady-state photoluminescence (PL), ultraviolet and visible (UV-Vis) absorption, and timeresolved PL (TRPL) spectroscopy. The open circuit voltage $\left(V_{\mathrm{oc}}\right)$ and fill factor (FF) of the PSCs were effectively improved, and a PCE of $20.72 \%$ was achieved.

\section{EXPERIMENTAL SECTION}

Perovskite film fabrication

$\mathrm{CH}_{3} \mathrm{NH}_{3} \mathrm{Br}, \mathrm{CH}_{5} \mathrm{~N}_{2} \mathrm{I}, \mathrm{CsI}, \mathrm{PbI}_{2}$ and $\mathrm{PbBr}_{2}$ were dissolved in a mixed solvent of DMF and DMSO $(4: 1, v / v)$ at a molar ratio of 3:16:1:17:3 to form a perovskite precursor solution of $1.4 \mathrm{~mol} \mathrm{~L}^{-1}$. A one-step fast crystallization method was used to prepare the film. Thirty microliters of the abovementioned solution was deposited onto the top of the dried mesoporous $\mathrm{TiO}_{2}$ electron transport layer, and then the substrate was immediately spin-coated at $2000 \mathrm{r} \mathrm{min}^{-1}$ for $10 \mathrm{~s}$. After that, $100 \mu \mathrm{L}$ of $\mathrm{PhCl}$ was dripped onto the substrate as the spinning speed was increased to $6000 \mathrm{r} \mathrm{min}^{-1}$ for $15 \mathrm{~s}$ and maintained at that speed for $30 \mathrm{~s}$. The spin-coated film was immediately transferred into a closed space on a hot plate with different volumes (5 to $60 \mu \mathrm{L}$ ) of anti-solvent $(\mathrm{PhCl}$ or $o$ $\mathrm{PhCl}_{2}$ ). After annealing at $100^{\circ} \mathrm{C}$ for $1 \mathrm{~h}$, the anti-solvent induced films were obtained. As a control, a spin-coated perovskite film was annealed at $100^{\circ} \mathrm{C}$ for $1 \mathrm{~h}$.

\section{Device preparation}

Solar cells with fluorine-doped tin oxide $(\mathrm{FTO}) / \mathrm{c}-\mathrm{TiO}_{2} /$ $\mathrm{m}-\mathrm{TiO}_{2} /$ perovskite/Spiro-OMeTAD/Au were prepared. The FTO glass substrates were ultrasonically cleaned with detergent, deionized water, and ethanol, successively, and then blow-dried in argon. A filtered mixture solution of isopropyl alcohol $(10 \mathrm{~mL})$, acetylacetone $(570 \mu \mathrm{L})$, and acetylacetonate titanate $(870 \mu \mathrm{L})$ was sprayed on an FTOcoated substrate under oxygen flow and then heated on a hot plate at $450^{\circ} \mathrm{C}$ for $5 \mathrm{~min}$. The mesoporous layer and hole transporting layer (HTL) were prepared by the spincoating method according to our previous studies [23], and the perovskite active layer was obtained based on the aforementioned method. Finally, $80 \mathrm{~nm}$ Au was deposited on the HTL by evaporation through a shadow mask under high vacuum. The active device area was $0.12 \mathrm{~cm}^{2}$.

\section{Characterizations}

The XRD patterns of the perovskite films prepared under different conditions were taken on a Rigaku Mini Flex 600 diffractometer with $\mathrm{Cu} \mathrm{Ka}$ radiation to identify the crystal phase transition process. The top-view and crosssectional morphologies of the perovskite films were recorded on a SU8010 SEM operated at a voltage of $10 \mathrm{kV}$. The absorption spectra of the perovskite films were characterized by a Thermo Evolution 300 UV/Visible spectrometer. The PL and TRPL spectra were measured by a Horiba FluoroMax-4 fluorescence spectrometer, in which the excitation source was a laser with a wavelength of $510 \mathrm{~nm}$. The atomic force microscopy (AFM) images of the perovskite films were taken using a Dimension icon (Bruker, Germany) to characterize the surface roughness. Glass substrates were utilized for XRD, UV-Vis, PL and 
TRPL, while $\mathrm{FTO} / \mathrm{c}-\mathrm{TiO}_{2} / \mathrm{m}-\mathrm{TiO}_{2}$ substrates were used for SEM and AFM. Electrochemical impedance spectroscopy (EIS) was performed using a SRC-1000-TC-QZ-C electrochemical workstation with an alternating current amplitude of $10 \mathrm{mV}$. The current density-voltage $(J-V)$ curves and the maximum power point of PSCs were measured with a Keithley 2400 source using a solar simulator (Solarbeam-2, Crowntech) with $100 \mathrm{~mW} \mathrm{~cm}^{-2}$ irradiation (AM 1.5 G). The incident monochromatic photon-electron conversion efficiency (IPCE) was recorded using a solar cell spectral response test system (E0201a, Institute of Physics, Chinese Academy of Sciences).

\section{RESULTS AND DISCUSSION}

\section{Crystal phase transition of perovskite film}

To examine the effect of anti-solvent vapor molecules on the secondary growth of perovskite films, a $2.8 \mathrm{~cm}^{3}$ enclosed space on hot plate was designed, and the influence of the film annealing $(1 \mathrm{~h})$ on the perovskite crystallization process was investigated under $o-\mathrm{PhCl}_{2}$ or $\mathrm{PhCl}$ vapor, as illustrated in Fig. 1.

Comparing the XRD patterns of perovskite films under different conditions, an obvious crystal phase transition is observed, as shown in Fig. 2a. Curve 1 shows the XRD pattern of perovskite film before annealing at room temperature (RT), revealing main diffraction peaks at $2 \theta=14.02^{\circ}, 24.90^{\circ}$, and $28.40^{\circ}$, which correspond to the (110), (202), and (220) crystal planes of tetragonal perovskite, respectively. A clear diffraction peak is detected at $6.80^{\circ}$ (Fig. $2 \mathrm{~b}$ ), which is assigned to the DMF/DMSO solvation-induced intermediate phase that forms during perovskite crystallization process; curve 6 of the perovskite film annealed at $100^{\circ} \mathrm{C}$ (control film) lacks this peak [24]. After the film was held for $1 \mathrm{~h}$, the diffraction peak of intermediate phase disappears (curve 2), while new diffraction peaks appear at $11.84^{\circ}$ and $12.44^{\circ}$, indicating that the intermediate phase decomposes to form $\delta$-phase of FA-based (FA, $\mathrm{CH}_{5} \mathrm{~N}_{2}{ }^{+}$, formamidine) perovskite and $\mathrm{PbI}_{2}(001)$ at RT, respectively. Similarly, the perovskite films were placed in an $o-\mathrm{PhCl}_{2}$ (curve 3) or $\mathrm{PhCl}$ (curve 4) atmosphere at $\mathrm{RT}$ for $1 \mathrm{~h}$; these films exhibit a significant enhancement in the diffraction peak at $14.02^{\circ}$, indicating an increased degree of crystallinity corresponding to the (110) crystal plane of perovskite film. Additionally, the typical peak of the intermediate phase still exists, confirming that the anti-solvent atmosphere can suppress the decomposition of intermediate phase and induce the secondary growth of perovskite grains. For comparison, a perovskite film was held in a DMF atmosphere for 1 min under the same conditions. As seen from curve 5 , the diffraction peak intensities at $2 \theta$ $=14.02^{\circ}, 24.90^{\circ}$, and $28.40^{\circ}$ obviously decrease, the baseline noise increases, and many impurity diffraction peaks appear. It is noteworthy that the diffraction peak of intermediate phase perovskite is still maintained. Moreover, it can be seen that the film in DMF atmosphere changes from brown to yellow within $5 \mathrm{~min}$ and then turns white, which indicates that the perovskite crystal is seriously damaged $[14,25]$. Consequently, both the antisolvent and polar solvent atmospheres can promote the stability of intermediate phase at RT, but the enhanced diffraction peak at $2 \theta=14.02^{\circ}$ for the film in anti-solvent atmosphere indicates the presence of a secondary growth process.

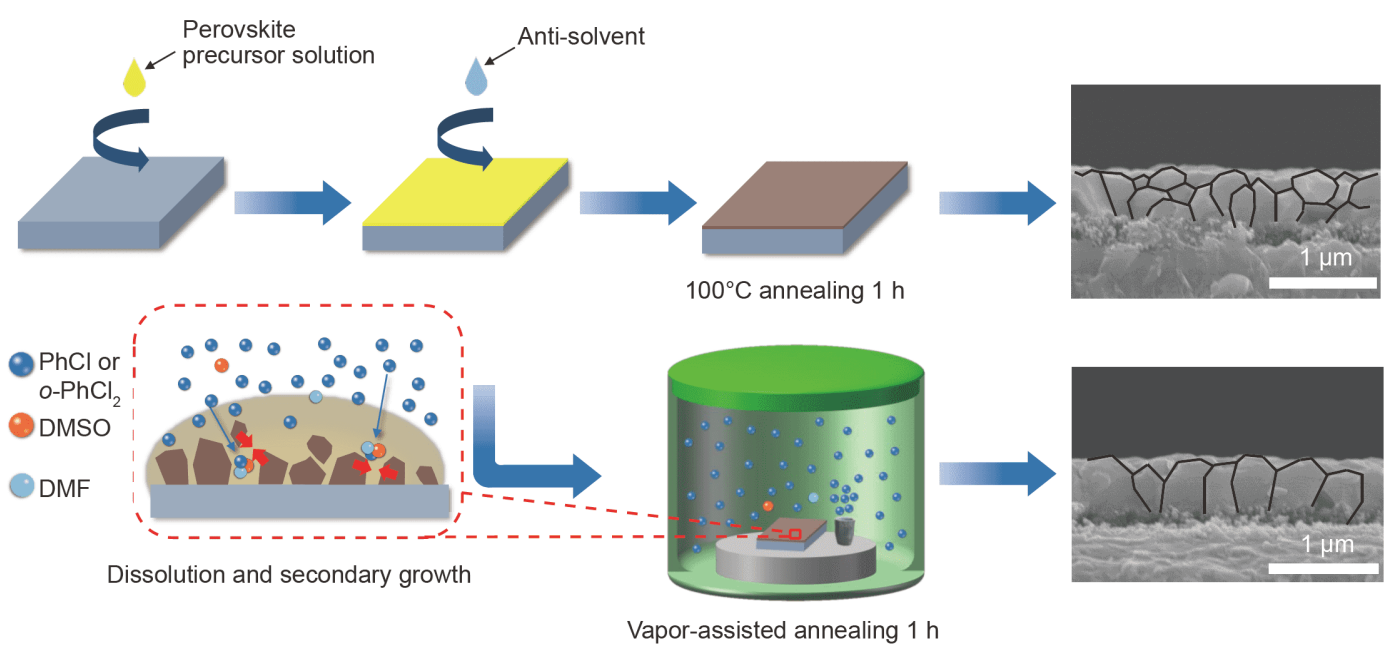

Figure 1 Schematic diagram of secondary growth process of perovskite film induced by anti-solvent vapor molecules. 

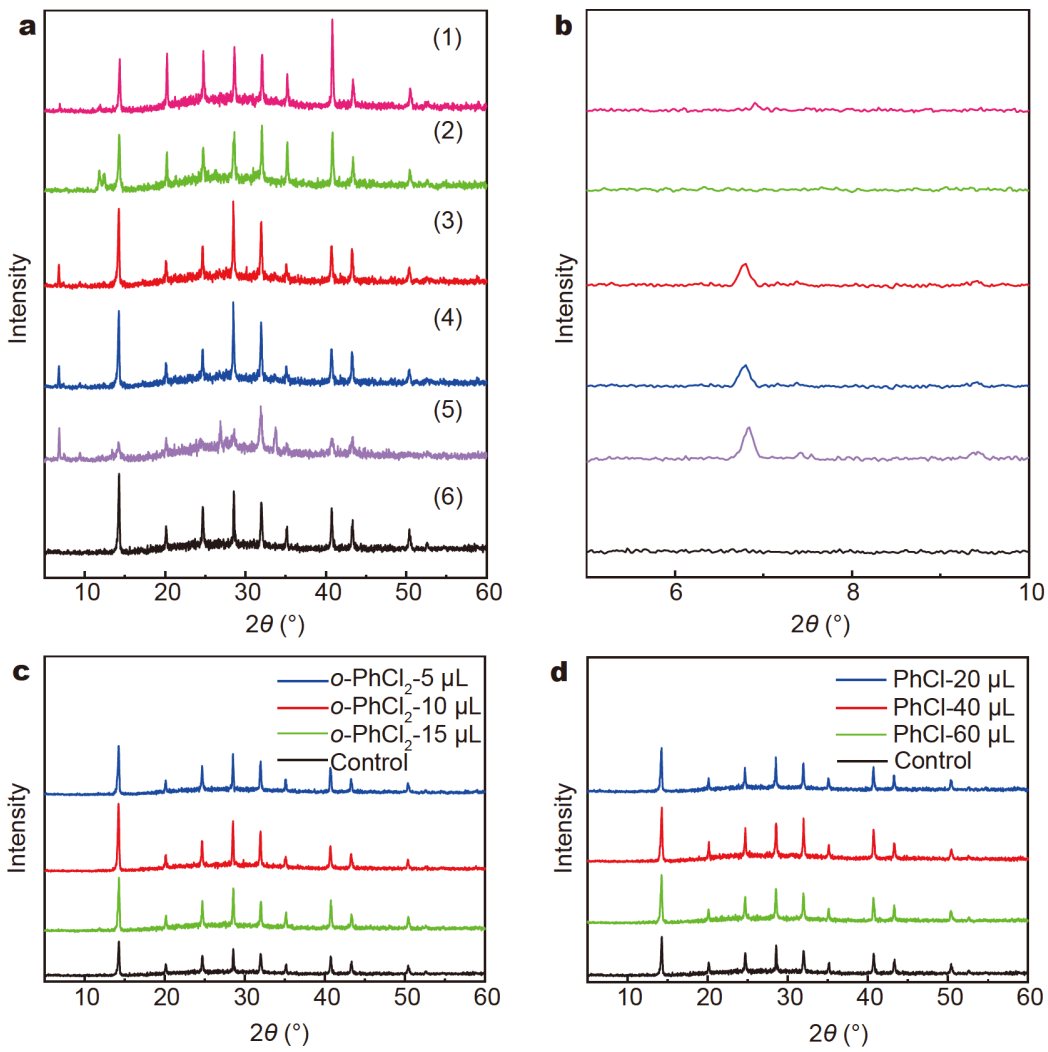

Figure 2 (a) XRD patterns of perovskite films and (b) local enlarged XRD patterns: (1) before annealing, (2) kept at RT for $1 \mathrm{~h}$, (3) kept in $o$-PhCl atmosphere at $\mathrm{RT}$ for $1 \mathrm{~h}$, (4) kept in $\mathrm{PhCl}$ atmosphere at $\mathrm{RT}$ for $1 \mathrm{~h}$, (5) kept in DMF atmosphere at RT for $1 \mathrm{~min},(6)$ annealed at $100^{\circ} \mathrm{C}$ for $1 \mathrm{~h}$ without anti-solvent (control film). XRD patterns of perovskite films annealed in different vapors $\left(100^{\circ} \mathrm{C}\right)$ : (c) $o$ - $\mathrm{PhCl}_{2} ;(\mathrm{d}) \mathrm{PhCl}$ and without antisolvent vapor.

Fig. 2c, d depict the XRD patterns of the perovskite films annealed in $o-\mathrm{PhCl}_{2}$ or $\mathrm{PhCl}$ vapor at $100^{\circ} \mathrm{C}$ for $1 \mathrm{~h}$. The vapor generated from different volumes of $o-\mathrm{PhCl}_{2}(5$ to $15 \mu \mathrm{L})$ or $\mathrm{PhCl}(20$ to $60 \mu \mathrm{L})$ can significantly enhance the diffraction peak intensity of perovskite films compared with that of control film. As the $o-\mathrm{PhCl}_{2}$ or $\mathrm{PhCl}$ volume increases, the diffraction peak intensity at $2 \theta=$ $14.02^{\circ}$ obviously increases, and the diffraction peak height reaches a maximum when the added volumes of $o-\mathrm{PhCl}_{2}$ and $\mathrm{PhCl}$ are 10 and $40 \mu \mathrm{L}$, respectively. Calculating the vapor pressure of the enclosed space by the Antoine equation [26] and the Ideal Gas Law [27,28] (Supplementary information, and the detailed parameters in Tables S1, S2), the added volume of $o-\mathrm{PhCl}_{2}(10 \mu \mathrm{L})$ and $\mathrm{PhCl}(40 \mu \mathrm{L})$ just reaches saturated vapor at $100^{\circ} \mathrm{C}$. With a further increase in the anti-solvent volume, the vapor pressure remains unchanged, which results in a stable effect on the secondary crystallization process of perovskite film. Therefore, the promotion of secondary grain growth and film crystallinity achieve greatest extent in the saturated vapor of anti-solvent.
The secondary growth mechanism of the perovskite grains The XRD results obtained under different conditions support that anti-solvent vapor molecules can induce the secondary growth of perovskite grains. Thus, it is necessary to clarify the mechanism of this process. SEM images of the perovskite films annealed with or without antisolvent saturated vapor were measured, as shown in Fig. 3.

The morphology and particle size of perovskite films were characterized by SEM, as depicted in Fig. 3a-c. After being annealed in anti-solvent vapor at $100^{\circ} \mathrm{C}$ for $1 \mathrm{~h}$, the grain size of perovskite film significantly increases. The average size is $500 \mathrm{~nm}$, the maximum particle size is $1 \mu \mathrm{m}$, and its distribution fits the normal distribution (insets of Fig. 3a-c). Compared Fig. 3b, c with Fig. 3a, the crystallites can be hardly observed on the perovskite film surface prepared in anti-solvent saturated vapor and the roughness of the best film decreases from $18.2 \mathrm{~nm}$ (control device) to $11.4 \mathrm{~nm}\left(o-\mathrm{PhCl}_{2}\right)$ and $13.7 \mathrm{~nm}(\mathrm{PhCl})$ (Fig. S1). These results indicate that the crystallites disappear during anti-solvent annealing, which can be at- 

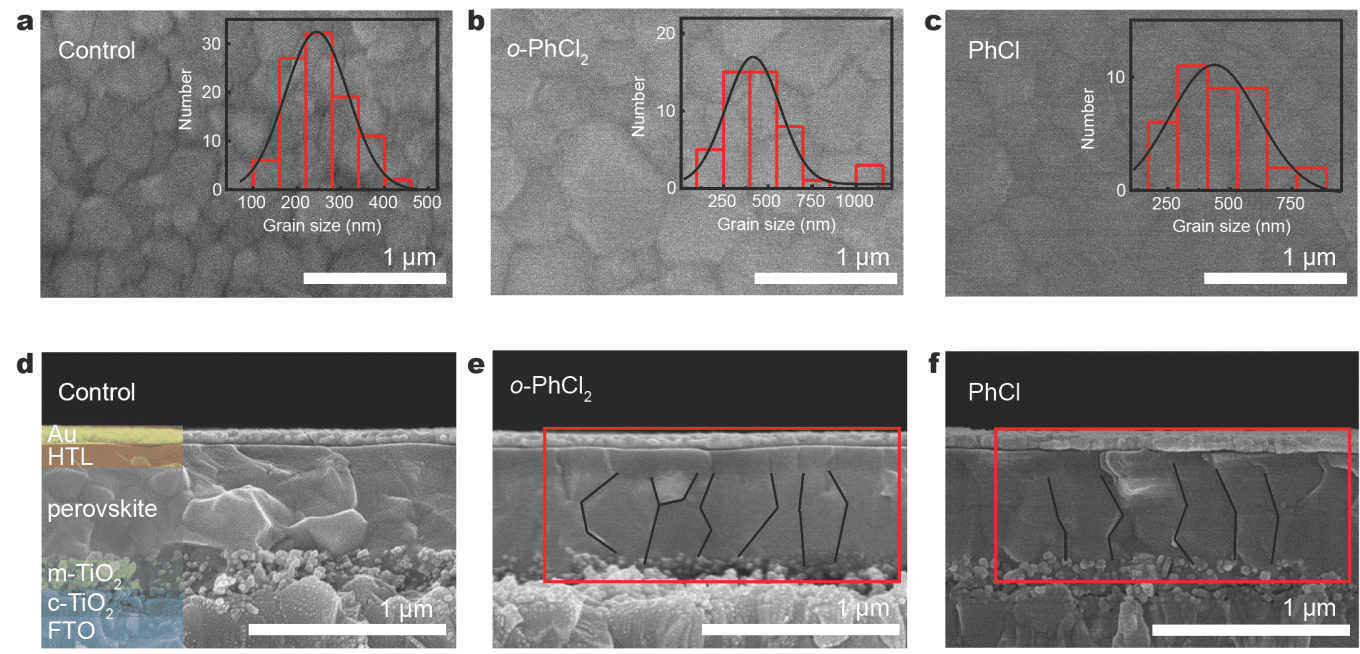

Figure 3 Top-view and cross-sectional SEM images of perovskite films deposited on mesoporous $\mathrm{TiO}_{2}$ layer under different annealing conditions: (a, d) without anti-solvent; (b, e) $10 \mu \mathrm{L} o-\mathrm{PhCl}_{2}$; (c, f) $40 \mu \mathrm{L} \mathrm{PhCl}$. The insets in (a-c) show the distributions of particle sizes.

tributed to the dissolution of crystallites induced by antisolvent molecules. This process effectively promotes grain growth and grain boundary reduction, which leads to a smooth film.

A one-step fast crystallization method [29] for perovskite film preparation is to drop an appropriate amount of anti-solvent $\mathrm{PhCl}$ onto a spin-coating film; the $\mathrm{PhCl}$ rapidly diffuses to form a mixture with DMF and DMSO, which can reduce the solubility of perovskite in the solvent and then crystallize it to form a crystalline film. Unevenly distributed grain sizes are usually derived from the abovementioned fast process, which leads to residual supersaturated perovskite solution at the grain boundaries of the film. On the one hand, the increase of system temperature during annealing process accelerates the evaporation rate of the solvent and promotes the further crystallization of the residual perovskite solution at the grain boundaries to form much smaller crystallites. On the other hand, the increased temperature improves the solubility of perovskite in mixed solvent which induces the dissolution of crystallites. The abovementioned two processes are competitive, and the annealing process without anti-solvent is dominated by the former. However, when the film is annealed in a closed environment, the vapor of anti-solvent molecules inhibits the evaporation of mixed solvent and promotes the dissolution of crystallites, and this inhibition effect reaches a maximum as the anti-solvent gas reaches saturation, which effectively reduces the perovskite crystallization rate to achieve a film with large grains, a high degree of crystallinity, and few grain boundaries. Both Fig. $3 e$ and
Fig. 3f show large grains of anti-solvent annealing film that can connect with the adjacent functional layers, while Fig. 3d presents irregular multilayered small grains, proving that the dissolution and secondary growth process actually exist.

Through a combination of the XRD and SEM results, a secondary growth mechanism of perovskite films annealed in anti-solvent vapor is proposed (Fig. S2). The dissolution of the crystallites and large grain surfaces is induced when the perovskite solubility increases. Afterwards, with the continuous evaporation of the solvent, the dissolved perovskite can uniformly crystallize along the surface of large grains or "weld" two or more adjacent surface-dissolved grains together to form larger grains throughout the thickness of the active film. The SEM images also shows that the film annealed in $o-\mathrm{PhCl}_{2}$ vapor is composed of larger grains than that annealed in $\mathrm{PhCl}$, and this may be related to $o-\mathrm{PhCl}_{2}$ possessing a higher boiling point which could more effectively prevent the evaporation of mixed solvent and promote the dissolution and secondary growth of the film. Moreover, an excessively polar solvent atmosphere during the annealing process leads to the decomposition of perovskite, which is not conducive to the improvement of film quality. This is also proven by the XRD results of curve 5 shown in Fig. 2a.

The films prepared with $o-\mathrm{PhCl}_{2}$ or $\mathrm{PhCl}$ annealing exhibit a smooth surface morphology in the low-magnification SEM images (Fig. S3d-f) while the control film presents bright cracked lines on the surface. In the highmagnification images, the cracked lines represent the 
accumulation of abundant crystallites and the formation of triple like scars (Fig. S3a-c), which further confirm the existence of secondary dissolution and recrystallization processes. For the control film, the rapid evaporation of mixed solvent during annealing is the main process, in which the residual perovskite solution at the grain boundaries rapidly reprecipitates from the mixed solvent and grows in situ into small grains. When the solvent completely evaporates, it forms bulging lines similar to stripe-like scars along the grain boundaries. Under the influence of $o-\mathrm{PhCl}_{2}$ or $\mathrm{PhCl}$ vapor, the evaporation rate of the mixed solvent is effectively suppressed, which results in the dissolution and continuous regrowth of crystallites. Consequently, the stripe-like scars of the film are eliminated, and the reduction in the grain boundaries and the passivation of the surface defects in the perovskite film are maximized.

\section{Photophysical properties and defect densities of the perovskite films}

The UV-Vis absorption, PL and TRPL spectra of the perovskite films annealed in different anti-solvent vapors under identical precursor concentrations are depicted in Fig. 4; glass substrates were used for the abovementioned tests. The UV-Vis spectra (Fig. 4a) show that whether annealed with or without anti-solvent vapor, the films exhibit intense absorption from 320 to $800 \mathrm{~nm}$, but the films annealed in $o-\mathrm{PhCl}_{2}$ or $\mathrm{PhCl}$ vapor present higher absorption intensity. Besides, the film annealed in $o$ $\mathrm{PhCl}_{2}$ vapor displays the highest absorption intensity in the full spectral range. This suggests that for a saturated vapor, the addition of $o-\mathrm{PhCl}_{2}$ can control the evaporation rate of DMSO and DMF more effectively than $\mathrm{PhCl}$ to obtain a high-quality film with few grain boundaries. Accordingly, such a light absorbing layer is conducive to achieving intense absorption in the full-spectrum [30]. The PL spectra shown in Fig. $4 \mathrm{~b}$ demonstrate a similar trend to the UV-Vis spectra, in which the emission intensities follow the order of $o-\mathrm{PhCl}_{2}>\mathrm{PhCl}>$ control and the maximum emission peak is blueshifted by approximately $2 \mathrm{~nm}\left(o-\mathrm{PhCl}_{2}\right.$ of $786 \mathrm{~nm}, \mathrm{PhCl}$ of $787 \mathrm{~nm}$, and control of $788 \mathrm{~nm}$ ). These results further indicate that after anti-solvent vapor annealing, the arrangement of molecules and the accumulation of unit cells in the perovskite crystal are more ordered, and the number of grain boundaries is reduced. The anti-solvent annealing process increases the film absorption from the UV to the visible region, which effectively excites the valence band electrons to the conduction band and increases the number of excitons due to the decreased grain boundaries and nonradiative recombination for excitons. Consequently, the fluorescence emission intensity is enhanced [31]. Fig. $4 \mathrm{c}$ presents the TRPL spectra of the perovskite films, and all the decay curves were fitted by a double exponential function. As expected, the calculated average lifetimes of the perovskite films annealed in anti-solvent saturated vapor significantly increase. The lifetime values of the $o-\mathrm{PhCl}_{2}$ and $\mathrm{PhCl}$ annealing films are 5.40 and $4.09 \mu \mathrm{s}$, respectively, while the lifetime of the control film is $3.24 \mu \mathrm{s}$, indicating that there are fewer defect states in the former two films, which causes the nonradiative annihilation of photoinduced excitons [32]. This facilitates the separation of excitons into carriers, thereby improving the short circuit current of the perovskite photovoltaic device. In addition, the stability of the film towards humidity and heat in dark was tested by XRD, as depicted in Fig. S4. The peak at $12.44^{\circ}$ assigned to $\mathrm{PbI}_{2}$ (001) appears after the film was exposed at $65 \pm 5 \%$ relative humidity $(\mathrm{RH})$ or $60^{\circ} \mathrm{C}$ for $30 \mathrm{~d}$, indicating that the perovskite film has partly decomposed. The ratio of $\mathrm{PbI}_{2}$ to perovskite $\left(2 \theta=14.02^{\circ}\right)$ of the control film increases faster than that of the perovskite film annealed in antisolvent vapor. The enhanced stability of the film is attributed to the effective reduction in the number of de-


Figure 4 Spectral characteristics of the perovskite films with and without anti-solvent annealing. (a) UV-Vis absorption spectra; (b) PL spectra with excitation wavelength of $510 \mathrm{~nm}$; (c) TRPL spectra. 
fects and grain boundaries.

The defect states in the active layers of solar cells lead to exciton annihilation and carrier recombination, which are associated with the grain size, crystallinity, and grain boundary density of the perovskite film. Herein, a device with the structure of indium-doped tin oxide (ITO)/poly (3,4-ethylenedioxythiophene):poly(styrene sulfonate) (PEDOT:PSS)/perovskite $/ \mathrm{MoO}_{3} / \mathrm{Au}$ was fabricated to measure the $J-V$ curves (Fig. 5a), where PEDOT:PSS and $\mathrm{MoO}_{3}$ were used as the hole injection layer and electron blocking layer, respectively. The density of the defect state in perovskite film was calculated by the space charge limiting current method (SCLC). In the low voltage range, the current density increases linearly with the bias voltage, indicating an ohmic contact. As the bias voltage increases, the curve exhibits a nonlinear steep rise, suggesting trap-limited conduction (TFL). The trap-filled limit voltage $\left(V_{\mathrm{TFL}}\right)$ can be defined as the voltage between the ohmic contact and the trap-filled region. Consequently, the defect density could be calculated by Equation (1) [33]:

$N_{\text {traps }}=\frac{2 \varepsilon_{0} \varepsilon V_{\mathrm{TFL}}}{e L^{2}}$,

where $\varepsilon_{0}$ is the vacuum permittivity of $8.85 \times 10^{-12} \mathrm{~F} \mathrm{~m}^{-1}, \varepsilon$ is the relative dielectric constant of 70 [34], $e$ is the elementary charge of $1.60 \times 10^{-19} \mathrm{C}$, and $L$ is the film thickness of $500 \mathrm{~nm}$. The $V_{\mathrm{TFL}}$ values of the perovskite films annealed in $o-\mathrm{PhCl}_{2}$ or $\mathrm{PhCl}$ saturated vapor and the control were calculated to be $0.26,0.31$, and $0.61 \mathrm{~V}$, and the defect densities were calculated by Equation (1) to be $8.046 \times 10^{15}, 9.593 \times 10^{15}$, and $1.888 \times 10^{16} \mathrm{~cm}^{-3}$, respectively. The defect density of the perovskite films annealed in anti-solvent vapors are 2.35 and 1.97-times less than that of the control, indicating that the anti-solvent annealing method effectively passivates the surface defects of per- ovskite film [35]. This result is consistent with the PL and TRPL results.

Fig. $5 \mathrm{~b}$ shows the EIS measurement of the PSCs with and without anti-solvent annealing in dark, and the inset of Fig. $5 \mathrm{~b}$ is the equivalent circuit. The series resistance $\left(R_{\mathrm{s}}\right)$ and charge transfer resistance $\left(R_{\mathrm{ct}}\right)$ were fitted from the EIS spectra to evaluate the quality of the perovskite film. Under a bias voltage of $1 \mathrm{~V}$, the values of $R_{\mathrm{s}}$ and $R_{\mathrm{ct}}$ for the device annealed in $o-\mathrm{PhCl}_{2}$ saturated vapor are 13 and $702.4 \Omega \mathrm{cm}^{2}$, those for the device annealed in $\mathrm{PhCl}$ saturated vapor are 20 and $674 \Omega \mathrm{cm}^{2}$, and those for the control device are 30 and $829.2 \Omega \mathrm{cm}^{2}$, respectively. From these results, it is concluded that the devices annealed in anti-solvent saturated vapor shows lower $R_{\mathrm{ct}}$ and $R_{\mathrm{s}}$, indicating the significant improvement in the film morphology [36].

\section{Device performance}

To investigate the effect of anti-solvent annealing on the device performance, the films annealed $\left(100^{\circ} \mathrm{C}\right)$ in $o$ $\mathrm{PhCl}_{2}$ or $\mathrm{PhCl}$ saturated vapor served as the active layer in $\mathrm{FTO} / \mathrm{c}-\mathrm{TiO}_{2} / \mathrm{m}-\mathrm{TiO}_{2} /$ perovskite/HTL/Au devices. The measured $J-V$ curves under AM $1.5 \mathrm{G}$ illumination $\left(100 \mathrm{~mW} \mathrm{~cm}^{-2}\right)$ are shown in Fig. 6a, and the photovoltaic parameters are summarized in Table 1 . The PCEs of the devices annealed in the saturated vapors of $o-\mathrm{PhCl}_{2}$ and $\mathrm{PhCl}$ are $20.72 \%$ and $19.49 \%$, respectively, which are remarkably improved than that of the control device (18.11\%). In particular, the FF values of the former two devices are greatly improved, which further confirms that the anti-solvent molecules can effectively promote the dissolution and ordered secondary growth of crystallites along the surface of large grains in the perovskite film. Moreover, the hysteresis loss of PSCs is significantly reduced, decreasing from $4.57 \%$ to $1.75 \%\left(o-\mathrm{PhCl}_{2}\right)$ and
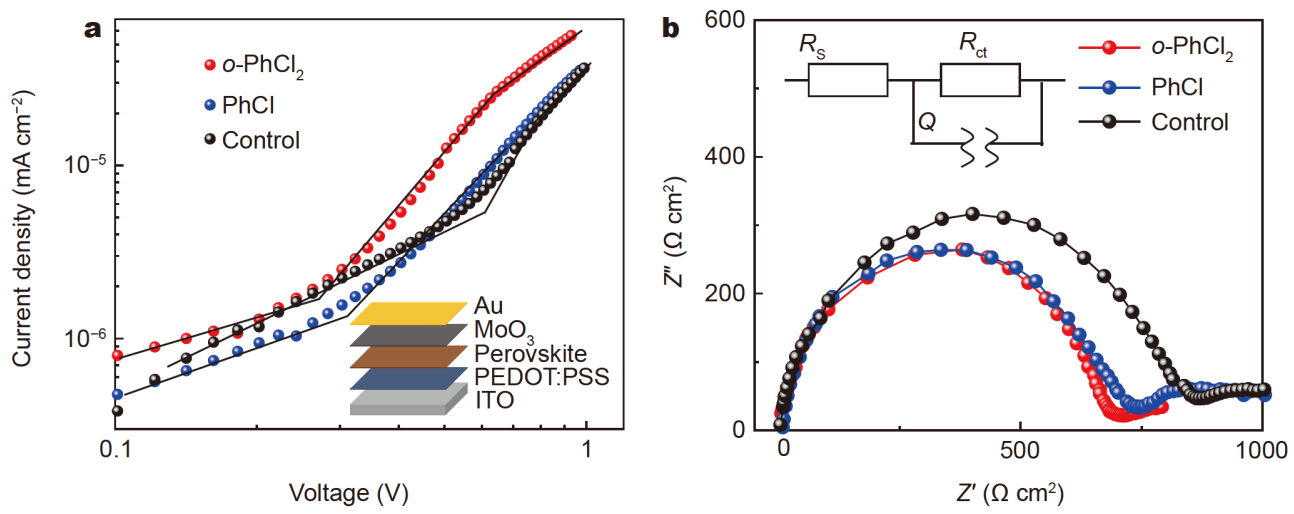

Figure 5 (a) $J-V$ curves of the ITO/PEDOT:PSS/perovskite/ $\mathrm{MoO}_{3} / \mathrm{Au}$ devices (the structure is shown as the inset) with and without anti-solvent annealing; (b) Nyquist plots of the PSCs measured in the dark at $1 \mathrm{~V}$ bias voltage. The inset is the equivalent circuit. 

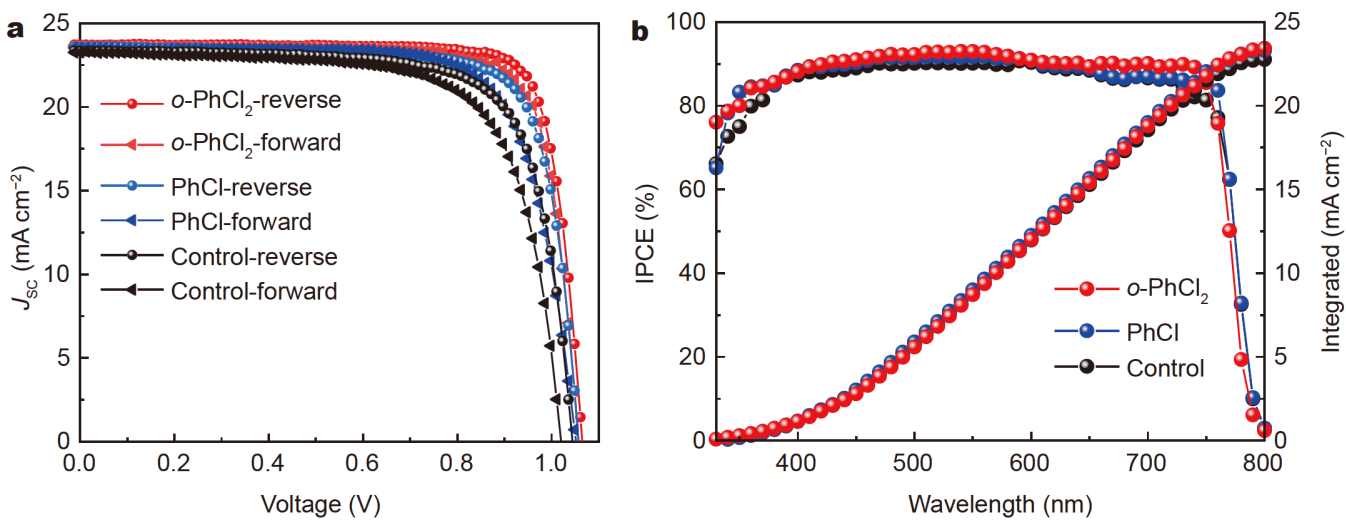

Figure 6 Device performances of PSCs with and without anti-solvent annealing. (a) $J$ - $V$ curves; (b) IPCE (scan rate: $10 \mathrm{~nm} \mathrm{~s}^{-1}$, active area: $0.16 \mathrm{~cm}^{2}$ ).

Table 1 Device parameters of the best-performing PCEs with or without anti-solvent annealing

\begin{tabular}{cccccc}
\hline Condition & Direction & $V_{\mathrm{oc}}(\mathrm{V})$ & $J_{\mathrm{sc}}\left(\mathrm{mA} \mathrm{cm}^{-2}\right)$ & FF & PCE \\
\hline \multirow{2}{*}{$o-\mathrm{PhCl}_{2}$} & Reverse & 1.07 & 23.72 & 0.82 & 20.72 \\
& Forward & 1.06 & 23.65 & 0.80 & 20.06 \\
\multirow{3}{*}{$\mathrm{PhCl}$} & Reverse & 1.06 & 23.57 & 0.78 & 19.49 \\
& Forward & 1.05 & 23.52 & 0.74 & 18.41 \\
\multirow{2}{*}{ Control } & Reverse & 1.04 & 23.34 & 0.74 & 18.11 \\
& Forward & 1.02 & 23.25 & 0.71 & 16.79 \\
\hline
\end{tabular}

$2.47 \%(\mathrm{PhCl})$ (the calculation process is described in Supplementary information), which indicates that this process can comprehensively upgrade the film quality, thereby increasing the device PCE.

The stabilized power output at the maximum power point (MPP) for the best performing devices was tracked for approximately $5 \mathrm{~min}$ in dehumidified ambient air (Fig. S5). The stabilized PCEs of $o-\mathrm{PhCl}_{2}$ and $\mathrm{PhCl}$ are $20.55 \%$ and $19.26 \%$, respectively, which is in good agreement with the PCEs obtained from the $J-V$ curves. Additionally, the stabilized PCE of the control device is $17.6 \%$, which is different from the result obtained from the $J$ - $V$ curves. The abovementioned results further suggest the superior performance of devices annealed in antisolvent vapor [37]. Fig. 6b illustrates the IPCE spectra of the PSCs. The $J_{\mathrm{sc}}$ values of the devices processed with $o$ $\mathrm{PhCl}_{2}, \mathrm{PhCl}$ and without anti-solvent calculated by integrating the IPCE curves are 23.51, 23.32 and $22.79 \mathrm{~mA} \mathrm{~cm}^{-2}$, respectively, which are close to the $J_{\mathrm{sc}}$ values obtained from the $J-V$ curves [38]. This enhancement in $J_{s c}$ is associated with the reduced carrier recombination, which occurs due to the formation of large grains throughout the thickness of the film, the reduction in grain boundaries, and the effective passivation of surface defects. The statistics of the performance para- meter distributions of eight devices for each condition are shown in Fig. S6. The average $V_{\text {oc }}$ and FF of the device annealed in $o-\mathrm{PhCl}_{2}$ saturated vapor are $1.07 \mathrm{~V}$ and 0.79 , and the device annealed in $\mathrm{PhCl}$ saturated vapor are $1.05 \mathrm{~V}$ and 0.78 , respectively. The significant increases in $V_{\text {oc }}$ and FF with narrow distributions for the devices annealed in anti-solvent saturated vapor indicate that this method possesses good reproducibility.

A storage stability test of unencapsulated PSCs under an indoor natural environment $(45 \pm 5 \% \mathrm{RH})$ was performed, as depicted in Fig. 7. The PCEs of the devices treated with $\mathrm{o}-\mathrm{PhCl}_{2}$ or $\mathrm{PhCl}$ exhibit slow downward trends, while a rapid reduction is observed for the control device. The devices annealed in $o-\mathrm{PhCl}_{2}$ or $\mathrm{PhCl}$ vapor remains at $85 \%$ and $78 \%$ of the initial PCE after $2400 \mathrm{~h}$, respectively. In contrast, the PCE of the control device decreases to $35 \%$ of its initial value under the same test conditions, which also strongly proves that the dissolution and secondary growth of perovskite grains induced by anti-solvent annealing could effectively passivate film defect and improve the film quality. This is an effective method for improving device stability.

\section{CONCLUSIONS}

In this work, a special anti-solvent vapor annealing 


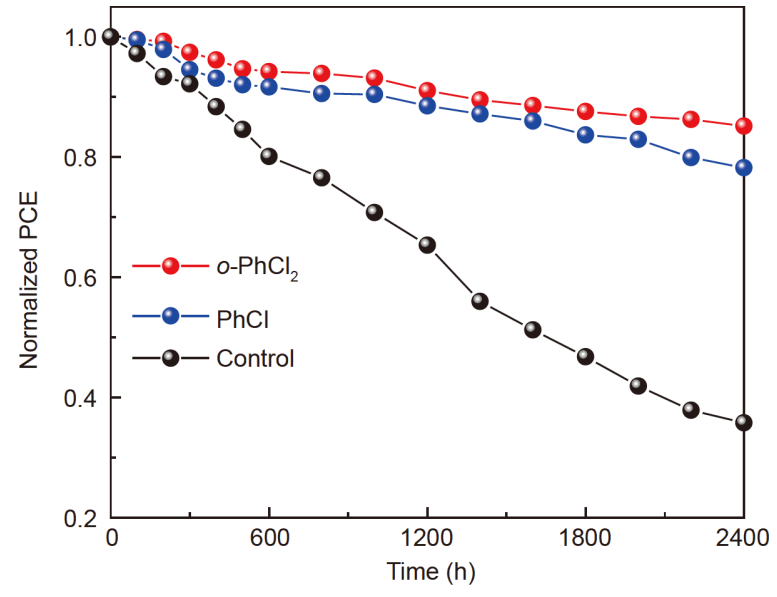

Figure 7 Evolution of the PCE for devices with and without antisolvent annealing under indoor natural environment aging.

strategy was demonstrated to induce the dissolution and ordered secondary growth of perovskite grains by $o-\mathrm{PhCl}_{2}$ or $\mathrm{PhCl}$. This process resulted in an increase in particle size, a reduction in grain boundaries, passivation of surface defects and improvement in the interface contact between the perovskite layer and transport layers. The anti-solvent molecules effectively suppressed the evaporation rate of DMF and DMSO between the perovskite grain boundaries, which resulted in the dissolution of crystallites and ordered regrowth along the surface of the grains or the "welding" of adjacent surface-dissolved grains, yielding large grains connected with the adjacent functional layers. The established annealing method did not introduce impurities, promoted the film quality, and greatly enhanced both the PCE and the stability of devices. In particular, the promotion effect was the best when the film was annealed in saturated vapor, and $o$ $\mathrm{PhCl}_{2}$, with a higher boiling point than $\mathrm{PhCl}$, could facilitate the process more effectively. The optimized device PCE reached 20.72\%, and the efficiency of the device remained $85 \%$ of the initial value after $2400 \mathrm{~h}$ treatment in natural environment at $45 \pm 5 \% \mathrm{RH}$.

Received 17 March 2020; accepted 1 June 2020; published online 25 August 2020

1 Saliba M, Matsui T, Seo JY, et al. Cesium-containing triple cation perovskite solar cells: Improved stability, reproducibility and high efficiency. Energy Environ Sci, 2016, 9: 1989-1997

2 Jiang Q, Chu Z, Wang P, et al. Planar-structure perovskite solar cells with efficiency beyond 21\%. Adv Mater, 2017, 29: 1703852

3 Correa-Baena JP, Abate A, Saliba M, et al. The rapid evolution of highly efficient perovskite solar cells. Energy Environ Sci, 2017, 10: $710-727$

4 NREL. Best Research-Cell Efficiency Chart | Photovoltaic Research | NREL. https://www.nrel.gov/pv/cell-efficiency.html accessed in
August 2019

5 Byranvand MM, Song S, Pyeon L, et al. Simple post annealing-free method for fabricating uniform, large grain-sized, and highly crystalline perovskite films. Nano Energy, 2017, 34: 181-187

6 Choi K, Choi H, Min J, et al. A short review on interface engineering of perovskite solar cells: A self-assembled monolayer and its roles. Sol RRL, 2019, 4: 1900251

7 Wolff CM, Caprioglio P, Stolterfoht M, et al. Nonradiative recombination in perovskite solar cells: The role of interfaces. Adv Mater, 2019, 31: 1902762

8 Li T, Pan Y, Wang Z, et al. Additive engineering for highly efficient organic-inorganic halide perovskite solar cells: Recent advances and perspectives. J Mater Chem A, 2017, 5: 12602-12652

9 Ahn N, Son DY, Jang IH, et al. Highly reproducible perovskite solar cells with average efficiency of $18.3 \%$ and best efficiency of $19.7 \%$ fabricated via lewis base adduct of lead(II) iodide. J Am Chem Soc, 2015, 137: 8696-8699

10 Zhang F, Shi W, Luo J, et al. Isomer-pure bis-PCBM-assisted crystal engineering of perovskite solar cells showing excellent efficiency and stability. Adv Mater, 2017, 29: 1606806

11 Yang S, Chen S, Mosconi E, et al. Stabilizing halide perovskite surfaces for solar cell operation with wide-bandgap lead oxysalts. Science, 2019, 365: 473-478

12 Arain Z, Liu C, Yang Y, et al. Elucidating the dynamics of solvent engineering for perovskite solar cells. Sci China Mater, 2019, 62: 161-172

13 Jiang Q, Zhao Y, Zhang X, et al. Surface passivation of perovskite film for efficient solar cells. Nat Photonics, 2019, 13: 460-466

14 Wang $\mathrm{Y}$, Li S, Zhang $\mathrm{P}$, et al. Solvent annealing of $\mathrm{PbI}_{2}$ for the high-quality crystallization of perovskite films for solar cells with efficiencies exceeding 18\%. Nanoscale, 2016, 8: 19654-19661

15 Yang Z, Babu BH, Wu S, et al. Review on practical interface engineering of perovskite solar cells: From efficiency to stability. Sol RRL, 2019, 4: 1900257

16 Xiao Z, Dong Q, Bi C, et al. Solvent annealing of perovskiteinduced crystal growth for photovoltaic-device efficiency enhancement. Adv Mater, 2014, 26: 6503-6509

17 Liu J, Gao C, He X, et al. Improved crystallization of perovskite films by optimized solvent annealing for high efficiency solar cell. ACS Appl Mater Interfaces, 2015, 7: 24008-24015

18 Xiao S, Bai Y, Meng X, et al. Unveiling a key intermediate in solvent vapor postannealing to enlarge crystalline domains of organometal halide perovskite films. Adv Funct Mater, 2017, 27: 1604944

19 Li B, Jiu T, Kuang C, et al. Chlorobenzene vapor assistant annealing method for fabricating high quality perovskite films. Org Electron, 2016, 34: 97-103

20 Yu H, Liu X, Xia Y, et al. Room-temperature mixed-solvent-vapor annealing for high performance perovskite solar cells. J Mater Chem A, 2016, 4: 321-326

21 Yuan B, Zhao S, Xu Z, et al. Improving the photovoltaic performance of planar heterojunction perovskite solar cells by mixed solvent vapor treatment. RSC Adv, 2018, 8: 11574-11579

22 Sun X, Zhang C, Chang J, et al. Mixed-solvent-vapor annealing of perovskite for photovoltaic device efficiency enhancement. Nano Energy, 2016, 28: 417-425

23 Zhao H, Wang S, Sun M, et al. Enhanced stability and optoelectronic properties of $\mathrm{MAPbI}_{3}$ films by a cationic surface-active agent for perovskite solar cells. J Mater Chem A, 2018, 6: 10825-10834 24 Petrov AA, Sokolova IP, Belich NA, et al. Crystal structure of 
DMF-intermediate phases uncovers the link between $\mathrm{CH}_{3} \mathrm{NH}_{3} \mathrm{PbI}_{3}$ morphology and precursor stoichiometry. J Phys Chem C, 2017, 121: 20739-20743

25 Cheng N, Li W, Yu Z, et al. Combined solvent and vapor treatment to prepare high quality perovskite films under high relative humidity. Electrochim Acta, 2017, 246: 990-996

26 Thomson GW. The Antoine equation for vapor-pressure data. Chem Rev, 1946, 38: 1-39

27 Kautz CH, Heron PRL, Shaffer PS, et al. Student understanding of the ideal gas law, Part II: A microscopic perspective. Am J Phys, 2005, 73: 1064-1071

28 Laugier A, Garai J. Derivation of the ideal gas law. J Chem Educ, 2007, 84: 1832-1833

29 Jeon NJ, Noh JH, Kim YC, et al. Solvent engineering for highperformance inorganic-organic hybrid perovskite solar cells. Nat Mater, 2014, 13: 897-903

30 Seol DJ, Lee JW, Park NG. On the role of interfaces in planarstructured $\mathrm{HC}\left(\mathrm{NH}_{2}\right)_{2} \mathrm{PbI}_{3}$ perovskite solar cells. ChemSusChem, 2015, 8: 2414-2419

31 Angmo D, Peng X, Seeber A, et al. Controlling homogenous spherulitic crystallization for high-efficiency planar perovskite solar cells fabricated under ambient high-humidity conditions. Small, 2019, 15: 1904422

32 Zhou H, Chen Q, Li G, et al. Interface engineering of highly efficient perovskite solar cells. Science, 2014, 345: 542-546

33 Carbone A, Pennetta C, Reggiani L. Trapping-detrapping fluctuations in organic space-charge layers. Appl Phys Lett, 2009, 95: 233303

34 Liao K, Yang JA, Li C, et al. Off-stoichiometric methylammonium iodide passivated large-grain perovskite film in ambient air for efficient inverted solar cells. ACS Appl Mater Interfaces, 2019, 11: 39882-39889

35 Aydin E, De Bastiani M, De Wolf S. Defect and contact passivation for perovskite solar cells. Adv Mater, 2019, 31: 1900428

36 Zarazua I, Han G, Boix PP, et al. Surface recombination and collection efficiency in perovskite solar cells from impedance analysis. J Phys Chem Lett, 2016, 7: 5105-5113

37 Zhu H, Liu Y, Eickemeyer FT, et al. Tailored amphiphilic molecular mitigators for stable perovskite solar cells with $23.5 \%$ efficiency. Adv Mater, 2020, 32: 1907757

38 Chen W, Shi Y, Wang Y, et al. N-type conjugated polymer as efficient electron transport layer for planar inverted perovskite solar cells with power conversion efficiency of $20.86 \%$. Nano Energy, 2020, 68: 104363

Acknowledgements This work was supported by the National Natural Science Foundation of China (21676188), the Science and Technology Plan Project of Tianjin (19ZXNCGX00020), and the National Key R\&D Program of China (2016YFB0401303).

Author contributions Liu $\mathrm{T}$ designed and engineered the samples; Li X conceived the post-fabrication tuning of random modes; Liu T and Li J performed the experiments; Liu T wrote the paper with support from Dong X and Li X. All authors contributed to the general discussion.

Conflict of interest The authors declare that they have no conflict of interest.
Supplementary information Experimental details and supporting data are available in the online version of the paper.

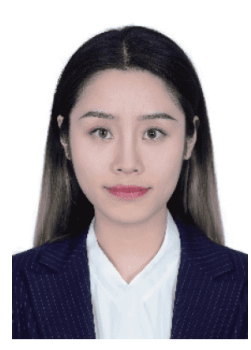

Tong Liu obtained her BS degree from Beijing University of Chemical Technology in 2017. She is currently a master candidate under the supervision of Prof. Xianggao Li in Tianjin University. Her research interests mainly focus on perovskite solar cells.

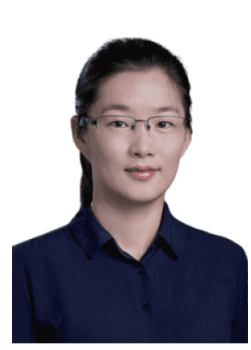

Xiaofei Dong received her PhD degree in 2018 from Tianjin University of Technology, Tianjin, China. She works as a postdoctoral fellow in Tianjin University, China. Her research interest focuses on the quantum dots and perovskite materials for optoelectronic device applications.

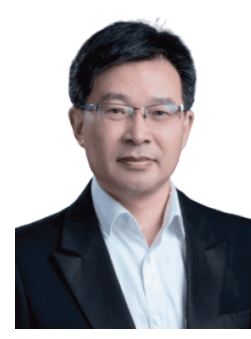

Xianggao Li received his BS degree from Hunan University and $\mathrm{PhD}$ degree from Tianjin University. In 2001, he joined the School of Chemical Engineering, Tianjin University as a full professor and was appointed as the director of Fine Chemical Engineering Department. His research interests include perovskite solar cells, organic/ quantum dots light-emitting diodes and metal halide perovskite nanocrystals.

\section{伴随式反溶剂工程控制钻钛矿晶粒二次生长及其 高效太阳能电池}

刘桐 ${ }^{1,2}$, 董晓菲 ${ }^{1,2 *}$, 黎俊聪 ${ }^{1,2}$, 刘红丽 1,2 , 王世荣 ${ }^{1,2}$, 李祥高 ${ }^{1,2^{*}}$

摘要 钙钛矿活性层的晶界数量和界面性质是影响太阳能电池性 能的关键因素. 本文建立了一种简单快捷的伴随退火工艺, 采用反 溶剂邻二氯苯 $\left(o-\mathrm{PhCl}_{2}\right)$ 或氯苯 $(\mathrm{PhCl})$ 抑制 $\mathrm{FA}_{0.80} \mathrm{MA}_{0.15} \mathrm{Cs}_{0.05} \mathrm{~Pb}$ $\left(\mathrm{I}_{0.85} \mathrm{Br}_{0.15}\right)_{3}$ 薄膜退火阶段溶剂分子的挥发, 诱导晶粒二次生长. 通 过X射线衍射(XRD)和扫描电子显微镜(SEM)研究了反溶剂分子对 钻钛矿薄膜晶相转变、晶界融合和形貌演化的影响, 阐明了反溶 剂分子能够有效抑制薄膜中溶剂挥发、促进微晶溶解并沿大晶粒 表面的二次有序生长的机制. 研究表明, 通过该反溶剂工程能够有 效增大活性层的晶粒尺寸, 钝化表面缺陷, 促进载流子的分离与传 输, 提高钙钛矿太阳能电池的能量转换效率( $\mathrm{PCE}$ )和稳定性. 由 0 $\mathrm{PhCl}_{2}$ 诱导二次生长的钻钛矿薄膜制备的器件PCE达到 $20.72 \%$, 在 室内自然环境, $45 \% \pm 5 \%$ 相对湿度下老化 $2400 \mathrm{~h}$, 电池的效率保持 在初始值的 $85 \%$ 以上. 